\title{
Effect of Cation Concentration and Radius, and Rheology on Nano-Scale Boehmite Aggregation
}

\author{
LM ANOVITZ1 ${ }^{1}$ P HuESTIS ${ }^{2}$, A.J. KRZYSKO ${ }^{3}$, JS

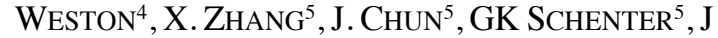 \\ ILAVSKY $^{6}$, I KUZMENKO $^{6}, \mathrm{MG} \mathrm{FRITH}^{6}, \mathrm{CF}$ IVORY $^{7}, \mathrm{SB}$ \\ CLARK $^{3}$, Katie M. WeIGANDT ${ }^{8}$, AG STACK $^{1}$, M

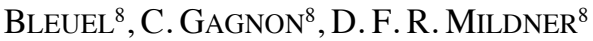

${ }^{1}$ Chem. Sci. Oak Ridge National Laboratory, Oak Ridge TN

${ }^{2}$ Physics, Univ. of Notre Dame, Notre DAme IN

${ }^{3}$ Dept. of Chemistry, Washington St. Univ., Pullman WA

${ }^{4}$ Chemical Engineering, Univ. of Tulsa. Tulsa OK

${ }^{5}$ Pacific NorthWest National Laboratory, Richland, WA

${ }^{6}$ Argonne National Laboratory, Argonne, IL

${ }^{7}$ Chemical Engineering, Washington St. Univ., Pullman WA

${ }^{8}$ NIST Center for Neutron Research, Gaithersburg, MD

The US government spends significant resources managing Cold War legacies, including 300 million liters of highly radioactive wastes in hundreds of tanks at Hanford (WA) and Savannah River (SC). The materials in these tanks consist of highly radioactive slurries at high $\mathrm{pH}$ and salt concentrations. The solids primarily consist of gibbsite and boehmite. These form complex aggregates that affect slurry rheology and efforts to recover and treat these wastes.

To better understand the effects of solution chemistry and rheology on particle aggregation we performed a series of tumbler (U)SANS, rheoUSANS and rheo(U)SAXS experiments on 20 weight percent solid solutions. Solutes consisted of $\mathrm{H}, \mathrm{Li}, \mathrm{Na}, \mathrm{K}$ and $\mathrm{Rb}$ nitrates at $10^{-5}$, to 4 molal, as well as in pure $\mathrm{H}_{2} \mathrm{O}$ and $\mathrm{pH}$ 9-13 $\mathrm{NaOH}$. Synthetic boehmite solids ranged from $\sim 20$ to $30 \mathrm{~nm}$. Although initial particles form individual rhombohedral platelets, in solution they form well-bonded primary aggregates up to $\sim 1500 \AA$ long. A second aggregate level was observed whose concentration and structure varies with cation type, concentration and shear. Aggregation generally increases with solute concentration and cation radius. Primary aggregates become more rod-like and larger. Shear-induced aggregation/ fragmentation was correlated to a balance between hydrodynamic and colloidal forces. Orientationally-dependent interactions, arising from non-spherical boehmite particles, led to the relatively large viscosities when the hydrodynamic force was small compared to colloidal forces, manifesting as moderate shear thinning even at low boehmite mass fractions. These data suggest that understanding the effects of salt concentration and chemistry on aggregate structures provides useful insights into the origin of slurry rheology in the Hanford wastes. 